\title{
POLÍTICAS PÚBLICAS: ANÁLISE DAS CONDIÇÕES DO HOSPITAL ESTADUAL MONSENHOR WALFREDO GURGEL
}

\author{
Silvania Matias Cavalcante ${ }^{378}$ \\ Ravênia Nagella Medeiros Dantas ${ }^{379}$
}

Recebido em: 19/04/2016

Aprovado em: 01/08/2016

\begin{abstract}
RESUMO
Analisa-se as políticas públicas no Brasil, de forma dialética, através de uma análise histórica, com base doutrinária no estudo dos direitos sociais, da cidadania e na visão clássica do Welfare State. Faz-se um estudo do ativismo judicial, que tem seu uso reputado como institucionalmente relevante e adequado à concretização das políticas públicas, pois diante da inércia de algumas instituições, passa o judiciário a desempenhar posturas para suprir essa omissão, fazendo com que os direitos fundamentais possam ser realizados. Busca-se, ainda, evidenciar a teoria desenvolvida num caso concreto, partindo de uma análise tópico-problemática, visando demonstrar a situação caótica da saúde no Estado do Rio Grande do Norte, enfatizando o problema dos leitos de UTI no Hospital Walfredo Gurgel e buscando uma solução prática para a resolução de tal problema, pautada no direito constitucional a saúde e na dignidade da pessoa humana. Estuda-se a tributação como mecanismo de mudanças sociais, uma vez que o tributo deve ser utilizado numa perspectiva extrafiscal, decorrente do intervencionismo estatal, representando a ação estatal sobre a sociedade, o mercado e a livre iniciativa. Por fim, busca-se demonstrar a forma como a tributação tem influenciado positivamente na implementação das políticas de inclusão social, em especial as ações afirmativas, que visam a inclusão social de grupos desfavorecidos ao longo da evolução da sociedade.
\end{abstract}

Palavras-chave: Políticas Públicas. Tributação. Direito Tributário.

\section{INTRODUÇÃO}

O presente artigo visa analisar as políticas públicas no Brasil, de forma dialética, através

\footnotetext{
378 Graduada em Direito pelo Centro Universitário do Rio Grande do Norte - UNIRN. Pós-Graduada em Direito Tributário pela Universidade Federal do Rio Grande do Norte - UFRN. Endereço eletrônico: silvaniacavalcante@yahoo.com.br.

${ }^{379}$ Graduada em Direito pela Universidade Federal do Rio Grande do Norte - UFRN. Pós-Graduada em Direito Tributário pela Universidade Federal do Rio Grande do Norte - UFRN.
} 
de uma análise histórica com base doutrinária no estudo dos direitos sociais, da cidadania e na visão clássica do Welfare State.

Faz-se um estudo do ativismo judicial, que tem seu uso reputado como institucionalmente relevante e adequado à concretização das políticas públicas, pois diante da inércia de algumas instituições, passa o judiciário a desempenhar posturas para suprir essa omissão, fazendo com que os direitos fundamentais possam ser realizados.

Busca-se, ainda, evidenciar a teoria desenvolvida num caso concreto, partindo de uma análise tópico-problemática, visando analisar a situação caótica da saúde no Estado do Rio Grande do Norte, enfatizando o problema dos leitos de UTI no Hospital Walfredo Gurgel e buscando uma solução prática para a resolução de tal problema, pautada no direito constitucional a saúde e na dignidade da pessoa humana.

O texto analisa a tributação como mecanismo de mudanças sociais, uma vez que o tributo deve ser utilizado numa perspectiva extrafiscal, decorrente do intervencionismo estatal, representando a ação estatal sobre a sociedade, o mercado e a livre iniciativa.

Por fim, o estudo busca demonstrar a forma como a tributação tem influenciado positivamente na implementação das políticas de inclusão social, em especial as ações afirmativas, que buscam a inclusão social de grupos desfavorecidos ao longo da evolução da sociedade.

\title{
2 BREVE ESTUDO SOBRE POLÍTICAS PÚBLICAS
}

\subsection{Direitos Sociais}

Consoante o ensinamento de MENDES; COELHO; BRANCO (p.710, 2008) ${ }^{380,}$

\begin{abstract}
Distintamente dos direitos civis e políticos, que tinham por objeto e/ou finalidade preservar determinados bens ou valores reputados naturais, inalienáveis e universais - como a vida, a liberdade e a propriedade - e, como titulares, sujeitos racionais, abstratamente declarados livres e iguais perante a lei, uma presunção que a realidade histórica prontamente demonstrou ser inconsistente, diversamente dos abstratos direitos de primeira geração, os direitos ditos sociais são concebidos como instrumentos destinados à efetiva redução e/ ou supressão de desigualdades, segundo a regra de que se deve tratar igualmente os iguais e desigualmente os desiguais, na medida da sua desigualdade.
\end{abstract}

Nesse mesmo diapasão, os autores acima mencionados citam na obra "Curso de Direito

${ }^{380}$ MENDES, G; COELHO, I; BRANCO, P. Curso de Direito Constitucional. 2 ed. São Paulo: Saraiva, 2008. 
Constitucional" ${ }^{381}$ uma afirmação de grande monta do jurista Andréas J. Krell ${ }^{382}$, na qual este traz que "A interpretação dos direitos sociais não é uma questão de lógica, mas de consciência social de um sistema jurídico como um todo". Assim, percebe-se que a efetivação dos direitos sociais não depende da vontade dos juristas, uma vez que se encontra ligada a fatores de ordem material.

Dalmo de Abreu Dallari ensina que não é suficiente "afirmar que todos são iguais perante a lei; é indispensável que sejam assegurados a todos, na prática, um mínimo de dignidade e igualdade de oportunidades". 383

Fábio Konder Comparato reza que os direitos sociais "se realizam pela execução de políticas públicas, destinadas a garantir amparo e proteção social aos mais fracos e mais pobres; ou seja, aqueles que não dispõem de recursos próprios para viver dignamente". 384

É importante mencionar que, no Brasil, a primeira Constituição que disciplinou os direitos sociais foi a de 1934, influenciada pela Constituição Alemã de 1919 de Weimar, que introduziu na Carta Magna a função social. ${ }^{385}$ Hoje, tais direitos se encontram nos artigos $6^{\circ}$ ao 11 da CRFB/88.

Diante do exposto, pode-se inferir que os direitos sociais são os direitos humanos também chamados de direitos da segunda geração, que tentam garantir o mínimo de dignidade e igualdade aos seres humanos e suprimir as desigualdades sociais, fazendo-se necessário que sua efetivação seja matéria de consciência social do sistema jurídico.

\subsection{Breves considerações sobre o "Welfare State"}

O Welfare State, também conhecido como Estado do bem-estar social, consiste numa visão clássica sobre o Estado. Consoante os ensinamentos de Hélio Jaguaribe ${ }^{386}$ apud Alcindo Gonçalves ${ }^{387}$, "O Welfare State, Estado Assistencialista, ou do bem-estar social, é uma construção europeia desenvolvida especialmente após a $2^{\text {a }}$ Guerra Mundial, representando "uma tentativa explícita ou implícita de implantar as ideias de democracia social"”.

381 MENDES, G; COELHO, I; BRANCO, P. Curso de Direito Constitucional. 2 ed. São Paulo: Saraiva, 2008 382 Andréas J. Krell, Direitos sociais e controle judicial no Brasil e na Alemanha, cit., p. 51.

383 DALLARI, Dalmo de Abreu. Direitos Humanos e Cidadania. $2^{\mathrm{a}}$ ed. reform. - São Paulo: Moderna, 2004, p. 46. 384 COMPARATO, Fábio Konder. A Afirmação Histórica dos Direitos Humanos. $7^{\text {a }}$ ed. rev. e atual. - São Paulo: Saraiva, 2010, p. 77.

385 SILVA, José Afonso da. Curso de Direito Constitucional Positivo. 32 ed. rev. e atual. - São Paulo: Malheiros Editores, 2009, p. 285.

386 JAGUARIBE, Hélio. Um estudo crítico da história. São Paulo: Paz e Terra, 2001. V.2. P. 597

387 GONÇALVES, Alcindo. Políticas públicas e a ciência política. In: BUCCI, Maria Paula Dallari (org.).

Políticas públicas: reflexões sobre o conceito jurídico. São Paulo: Saraiva, 2006 
Fábio Guedes Gomes ${ }^{388}$ menciona em seu artigo "Conflito social e Welfare State: Estado e desenvolvimento social no Brasil" que essa visão clássica do Estado pode ser compreendida como

\begin{abstract}
Um conjunto de serviços e benefícios sociais de alcance universal promovidos pelo Estado com a finalidade de garantir uma certa "harmonia" entre o avanço das forças de mercado e uma relativa estabilidade social, suprindo a sociedade de benefícios sociais que significam segurança aos indivíduos para manterem um mínimo de base material e níveis de padrão de vida, que possam enfrentar os efeitos deletérios de uma estrutura de produção capitalista desenvolvida e excludente.
\end{abstract}

Esping Andersen389 menciona que a Welfare State "envolve responsabilidade estatal no sentido de garantir o bem-estar dos cidadãos". É esse o pensamento aplicado no estudo das políticas públicas, no qual o Estado é o responsável por reunir o aparato que dispõe para proporcionar a sociedade o bem-estar social e condições dignas e justas de sobrevivência.

Percebe-se que o Welfare State foi o precursor dos ideais de que o Estado é o agente responsável pela democracia social, visto que é através do poder governamental que resultam todos os outros processos reguladores da sociedade, que proporcionam a efetivação dos direitos sociais conferidos na Constituição Federativa da República Brasileira de 1988. Tal visão será abordada com maior precisão no próximo tópico, que conceitua e explana as políticas públicas.

\title{
2.3 Definição de Políticas Públicas
}

É inegável a importância que as políticas públicas, como instrumentos legítimos de efetivação de direitos fundamentais, assumem no Estado Constitucional. Segundo Marcus Aurélio de Freitas Barros no artigo O Ministério Público social e o controle de políticas públicas no Brasil ${ }^{390}$,

As políticas públicas apresentam-se como instrumentos (programas de ação estatais) indispensáveis para a efetivação de alguns direitos fundamentais (prestacionais) onde não é suficiente a ação do legislador, mas necessária à ação planejada do Estado à luz dos recursos disponíveis.

Corroborando com o exposto, Antoni Fernandéz ${ }^{391}$ menciona que “a inação (omissão) governamental gera um impacto sobre a sociedade tão importante quanto o das ações estatais".

388 GOMES, Fábio Guedes. Conflito social e Welfare State: Estado e desenvolvimento social no Brasil. Disponível em: < http://www.scielo.br/pdf/rap/v40n2/v40n2a03.pdf>. Acesso em: 13 nov. 2013.

389 Gosta Esping-Andersen. As três economias políticas do Welfare-State. Lua nova, n.24, setembro de 2001. 390 BARROS. Marco Aurélio de Freitas. O ministério público social e o controle de políticas públicas no Brasil. Revista Pesquisas Jurídicas. Vol.01, n.1. jul-dez. 2012.

391 FERNANDÉZ, Antoni. Las políticas públicas. In: BADIA, Miquel Caminal (Editor). Manual de Ciencia Política. 3 ed. Madrid: Tecnos, 2010. 
Alcindo Gonçalves na obra "Políticas Públicas e a ciência política", suscita que as definições de políticas públicas são tendenciosas a colocar o Estado como "O agente central de sua promoção, constituindo-se sistematicamente em ações de governos". O autor cita como exemplo o ministro do Supremo Tribunal Federal Eros Grau, que conceitua Políticas Públicas como "Todas as atuações do Estado, cobrindo todas as formas de intervenção do Poder Público na vida social".

Maria Paula Dallari Bucci sintetiza Políticas Públicas como sendo

O programa de ação governamental que resulta de um processo ou de um conjunto de processos juridicamente regulados- processo eleitoral, processo de planejamento, processo de governo, processo orçamentário, processo legislativo, processo administrativo, processo judicial.

Marcus Aurélio de Freitas Barros demonstra de forma clara em seu artigo supramencionado a importância da sociedade na formulação e acompanhamento das políticas públicas, conforme trecho que segue:

Inegável, portanto, que o planejamento, definição e execução das políticas públicas encontram-se, primariamente, no plexo de responsabilidades dos poderes políticos. Contudo, não se pode deixar de ressaltar o papel da sociedade, por intermédio dos Conselhos de Políticas Públicas (muitos deles deliberativos), das ouvidorias e do cidadão (através, por exemplo, do orçamento participativo) na formulação e acompanhamento das políticas públicas. As responsabilidades, portanto, de modo geral, são exercidas por intermédio de modelos de democracia representativa e participativa.

Destarte, faz-se mister prever mecanismos que controlem as políticas públicas. Existe o controle político, que é aquele exercido pelos poderes políticos através do debate parlamentar; o controle social e o papel dos Conselhos e das ouvidorias; e por fim, o controle jurisdicional, exercido por intermédio da jurisdição constitucional. ${ }^{392}$

Diante dos conceitos acima expostos, pode-se inferir que Políticas Públicas consistem em instrumentos legítimos de efetivação de direitos fundamentais resultantes do estudo de um conjunto de processos interligados para realizarem projetos úteis e necessários à sociedade, formulados de acordo com os recursos estatais disponíveis, pondo em prática, dessa forma, os programas de ação governamental.

2.4 Cidadania e políticas públicas

392 BARROS, Marco Aurélio de Freitas. O ministério público social e o controle de políticas públicas no Brasil. Revista Pesquisas Jurídicas. Vol.01, n.1. jul-dez. 2012. 
O tema "cidadania" é imperioso no ordenamento jurídico brasileiro. Tanto é que foi abarcado no art. $1^{\circ}$, I da Carta Magna como fundamento do Estado democrático de Direito, ex positis:

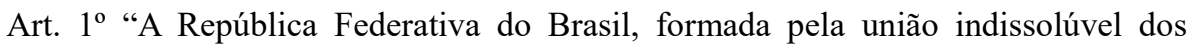
Estados e Municípios e do distrito Federal, constitui-se em Estado democrático de Direito e tem como fundamentos:

I- a Soberania, II- a cidadania, III- a dignidade da pessoa humana, IV- os valores sociais do trabalho e da livre iniciativa; V- o pluralismo político".

A compreensão do significado da cidadania ocorreu a partir do estudo clássico do sociólogo Theodore Humprhey Marshall 393 "Cidadania e classe social”, de 1950, que fala sobre a extensão dos direitos civis, políticos e sociais para toda a população de uma nação. Tais direitos foram enfatizados com o fim da $2^{\text {a }}$ Guerra Mundial, após 1945, com a criação Welfare State, abordado em tópico anterior do presente artigo.

Conforme o historiador José Murilo de Carvalho, a trajetória dos direitos no Brasil seguiu lógica inversa à descrita por Marshall. Primeiramente, vieram os direitos sociais, implantados em período de supressão dos direitos políticos e de redução dos direitos civis por um ditador que se tornou popular (Getúlio Vargas). Somente depois vieram os direitos políticos. A expansão do direito do voto deu-se em outro período ditatorial, em que os órgãos de repressão política foram transformados em peça decorativa do regime militar. A pirâmide dos direitos foi colocada de cabeça para baixo. ${ }^{394}$

Marshall afirma em sua obra Cidadania, classe social e status ${ }^{395}$ que a cidadania só se torna plena quando revestida pelos direitos civil, político e social. Os primeiros são aqueles que abarcam a liberdade individual, a liberdade de expressão e a de pensamento, o direito a propriedade, de conclusão de contratos e o direito à justiça, que foram constituídos no século XVIII; O segundo assegura o direito de participação no exercício político, constituído no século XIX; O último reflete o conjunto de direitos relativos ao bem-estar social e econômico, que ganharam ênfase no século XX. ${ }^{396}$

Maria Helena Diniz entende a cidadania como pertencente à seara da Ciência Política $\mathrm{e}$ a descreve como sendo "a qualidade ou estado de cidadão; vínculo político que gera para o nacional deveres e direitos políticos, uma vez que o liga ao Estado. É a qualidade de cidadão

393 MARSHALL, T. H. Cidadania, classe social e status. Rio de Janeiro: Zahar, 1967.

394 CARVALHO, José Murilo. Cidadania no Brasil: o longo caminho. Rio de Janeiro: Civilização Brasileira, 2001. p. 219-29.

395 MARSHALL, T. H. Cidadania, classe social e status. Rio de Janeiro: Zahar, 1967.

396 CAMARGO, Orson. O que é cidadania? Brasil escola. Disponível em:

<http://www.brasilescola.com/sociologia/cidadania-ou-estadania.htm〉. Acesso em: 13 nov. 2013. 
relativa ao exercício das prerrogativas políticas outorgadas pela Constituição de um Estado democrático". 397

Para Bittar ${ }^{398}$, cidadania remonta a uma tradição jurídica e exprime que ser cidadão "É ser parte de um Estado soberano, cuja adesão lhe concede certo status, bem como votar e poder ser votado". (p.8-9, 2004)

A cidadania encontra-se intimamente ligada aos princípios da igualdade e da solidariedade, de forma a garantir direitos e deveres aos cidadãos e a tratar igualmente os iguais e desigualmente os desiguais.

$\mathrm{Na}$ fusão de políticas públicas com a cidadania, percebe-se que as políticas públicas visam reequilibrar as condições de inclusão, propondo-se a universalizar as possibilidades de integração pelo incremento da liberdade e da igualdade, neutralizando, dessa forma, as diferenças fáticas que desestabilizam os pontos iniciais. Assim, há a ampliação da concretização dos direitos fundamentais. ${ }^{399}$

Ante o exposto, nota-se que a cidadania é um tema de grande monta, garantida legalmente no art. $1^{\circ}$ da CRFB/88. Possui acepção ampla e histórica iniciada pelo sociólogo T.H. Marshall, que ficou conhecido pelos ideais de extensão dos direitos civis, políticos e sociais para toda a população. A cidadania só se torna plena quando revestida por estes três direitos. Além de tudo, a cidadania almeja equilibrar as condições de inclusão dos cidadãos, proporcionando direitos, deveres e garantindo direitos fundamentais, tais como a igualdade e a solidariedade.

\section{O ATIVISMO JUDICIAL NO CONTROLE DE POLÍTICAS PÚBLICAS}

Conforme mencionado anteriormente, em decorrência da distribuição de competências sistematizadas na Carta Magna, a implementação e concretização de políticas públicas são atribuições dos poderes executivos e legislativos, não podendo, em regra, o poder judiciário intervir em esfera reservada a outro poder para substituí-lo por juízo de conveniência de oportunidade.

Ocorre que na implementação das políticas públicas é essencial compreender o conceito

\footnotetext{
${ }^{397}$ DINIZ, Maria Helena. Dicionário Jurídico. Vol. 1. $2^{\text {a }}$ ed. São Paulo : Saraiva, 2005, p. 692.

398 BITTAR, Eduardo C.B. Ética, educação, cidadania e direitos humanos: Estudos filosóficos entre cosmopolitismo e responsabilidade social. São Paulo. Manole, 2004.

${ }^{399}$ PINTO, Flávia Souza Dantas. Conteúdo escrito em consonância com os slides ministrados em sala de aula no curso de especialização em Direito Tributário da UFRN. Natal: Outubro, 2013.
} 
de ativismo judicial, uma vez que seu uso é reputado como institucionalmente relevante e adequado à concretização destas, pois diante da inércia de algumas instituições, passa o judiciário a desempenhar posturas para suprir essa omissão, fazendo com que os direitos fundamentais possam ser realizados.

Nas lições do ministro Luís Roberto Barroso sobre o tema o mesmo aduz que:

O ativismo judicial é uma atitude, a escolha de um modo específico e proativo de interpretar a Constituição, expandindo o seu sentido e alcance. Normalmente ele se instala em situações de retração do Poder Legislativo, de um certo descolamento entre a classe política e a sociedade civil, impedindo que as demandas sociais sejam atendidas de maneira efetiva. ${ }^{400}$

Dessa forma, observa-se que a ideia de ativismo judicial está atrelada a uma participação mais veemente do Judiciário na concretização dos preceitos constitucionais, com maior interferência no âmbito de atuação dos poderes executivos e legislativos. A postura ativista é identificada por meio de diferentes condutas, quais sejam: (i) a aplicação direta da Constituição a situações não expressamente contempladas em seu texto e independentemente de manifestação do legislador ordinário; (ii) a declaração de inconstitucionalidade de atos normativos emanados do legislador, com base em critérios menos rígidos que os de patente e ostensiva violação da Constituição; (iii) a imposição de condutas ou de abstenções ao Poder Público, notadamente em matéria de políticas públicas.

No caso do Brasil, há uma grande preocupação quanto ao novo papel que o judiciário vem assumindo, com a superlativização de suas atribuições, todavia não se atentando para as causas dessa proatividade.

In casu, observa-se que o ativismo judicial se mostra em ascensão em decorrência da modificação do próprio modelo de Estado para um Estado democrático de direito/ Estado Social haja vista que grande parte dos direitos fundamentais assegurados da carta magna, especialmente os direitos sociais, não se concretizam sem uma intervenção externa.

Diante desse novo modelo vigente, verifica-se que a posição do juiz foi alterada, sendo ele corresponsável pelo sucesso das finalidades perseguidas pelo Estado social, uma vez que os mesmos não podem ficar inertes quando os órgãos do poder público se omitem ou retardam, excessivamente, o cumprimento das obrigações que estão sujeitos.

Assim, vê-se que o judiciário brasileiro tem apresentando uma postura cada vez mais ativista. Entretanto, é necessário destacar que esse mecanismo não pode ser dar de forma desenfreada, sendo necessário respeitar as margens de discricionariedade do poder legislativo,

\footnotetext{
${ }^{400}$.BARROSO, Luíz Roberto.Judicialização, ativismo judicial e legitimidade democrática. Acesso em http://www.oab.org.br/editora/revista/users/revista/1235066670174218181901.pdf
} 
desta maneira é correta tal intervenção apenas quando o legislador tiver procedido com a nítida intenção de neutralizar e/ou comprometer a eficácia dos direitos sociais, econômicos e culturais ou até mesmo ter procedido de forma desarrazoada.

Nessa linha de pensamento, seguem as manifestações do Ministros do STF Gilmar Mendes no MS 26.915/DF e Celso de Melo na Adin 4277/DF respectivamente:

\begin{abstract}
Assim, alternando momentos de maior e menor ativismo judicial, o Supremo tribunal federal, ao longo de sua história, tem entendido que a discricionariedade das medidas políticas não impede o seu controle judicial, desde que haja violação a direitos assegurados pela constituição. Mantendo essa postura, o Supremo tribunal federal, na última década, tem atuado ativamente no tocante ao controle judicial das questões políticas, nas quais observa violação à constituição. Os diversos casos levados recentemente ao tribunal envolvendo atos das comissões parlamentares de inquérito que corroboram essa afirmação. ${ }^{401}$

A colmatação de omissões constitucionais: um gesto de respeito pela autoridade da constituição da república. Nem se alegue, finalmente, no caso ora em exame, a ocorrência de eventual ativismo judicial exercido pelo STF, especialmente porque, dentre as inúmeras causas que justificam esse comportamento afirmativo do poder judiciário, de que resulta uma positiva criação jurisprudencial do direito, inclui-se a necessidade de fazer prevalecer a primazia da constituição da república, muitas vezes transgredidas e desrespeitada por pura e simples omissão do poder público. Na realidade, o STF, ao suprir omissões inconstitucionais dos órgãos estatais e ao adotar medidas que objetivem restaurar a constituição violada pela inércia dos poderes do Estado, nada mais faz senão cumprir sua missão constitucional e demonstrar, com esse gesto, o respeito incondicional que tem pela autoridade da lei fundamental. (...) ${ }^{402}$
\end{abstract}

Logo, vê-se que apesar dos argumentos contrários, o ativismo judicial tem relação direta com as políticas públicas desde que respeitados os limites assegurados na legislação.

\title{
4 O CONTROLE JUDICIAL EFETUADO NA SAÚdE: CASO DOS LEITOS DE UTI NO HOSPITAL WALFREDO GURGEL
}

No intuito de evidenciar a teoria desenvolvida num caso concreto, será analisada a situação caótica da saúde no Estado do Rio Grande do Norte enfatizando o problema dos leitos de UTI no Hospital Walfredo Gurgel, assunto o qual já foi objeto de várias ações judiciais no Estado, uma vez que $90 \%$ da população do Estado depende exclusivamente do sistema público e a estrutura do setor da saúde não tem capacidade para atender nem $50 \%$ desta demanda.

A saúde pública do RN enfrenta a maior crise de sua história. Há um caos generalizado no setor, com ausência de leitos, medicamentos e insumos. No que concerne ao HWG,

\footnotetext{
${ }^{401} \mathrm{MS} 26915 \mathrm{MC} / \mathrm{DF}$

${ }^{402}$ ADI 4277/DF
} 
diariamente, em média 40 pacientes em estado grave aguardam UTI e muitos morrem enquanto aguardam o atendimento.

Desse modo, com o fim de reverter esse quadro catastrófico, foi decretada situação de calamidade pública na tentativa de angariar recursos para o setor. Todavia, tal tentativa não obteve sucesso, pois a situação continua preocupante.

Diante de tal situação, cumpre-se ressaltar que o direito a saúde representa um direito de segunda geração o que confere ao indivíduo o direito de exigir do Estado prestações sociais no campo da saúde, educação, trabalho, expressamente previstas no art. $6^{\circ}$ da constituição federal. ${ }^{403}$ Por conseguinte, como forma de assegurá-los, é dever do Estado garantir mediante a criação de políticas que visem à redução dos riscos de doença e o acesso universal e igualitário às ações e serviços para sua proteção e recuperação.

Outrossim, é oportuno frisar que o nosso ordenamento jurídico é balizado pelo princípio da dignidade humana, insculpido no art. $1^{\circ}$, inciso III ${ }^{404}$ que se apresenta como fundamento da República federativa do Brasil.

Sobre esse fundamento constitucional, assevera Daniel Sarmento em sua obra $A$ constitucionalização do direito que:

\begin{abstract}
Na verdade, o princípio da dignidade da pessoa humana exprime, em termos jurídicos, a máxima Kantiana, segundo o qual o homem deve sempre ser tratado como um fim em si mesmo e nunca como um meio. O ser humano precede o Direito e o Estado, que apenas de justificam em razão dele. Nesse sentido, a pessoa humana deve ser concebida e tratada como valor fonte do ordenamento jurídico, como assevera Miguel Reale, sendo a defesa e promoção de sua dignidade, em todas suas dimensões, a tarefa primordial do Estado democrático de direito ${ }^{405}$
\end{abstract}

Neste passo, nota-se que o princípio da dignidade humana representa o epicentro valorativo da ordem constitucional, influenciando todo ordenamento jurídico e balizando não apenas os atos estatais, mas também as relações privadas. Por isso, pode ser dito que o princípio em comento é o que confere unidade de sentido e valor ao sistema constitucional, que repousa na ideia de proteção irrestrita ao ser humano, razão última do direito e do Estado. Em razão disso, a legislação pátria deve estabelecer preceitos que tutelam e garantem o direito a saúde.

Dessa maneira, existem várias diplomas legais que tutelam o direito a saúde, dentre

\footnotetext{
${ }^{403}$ Art. $6^{\circ}$ São direitos sociais a educação, a saúde, a alimentação, o trabalho, a moradia, o lazer, a segurança, a previdência social, a proteção à maternidade e à infância, a assistência aos desamparados, na forma desta Constituição.

404 Art. $1^{\circ}$ A República Federativa do Brasil, formada pela união indissolúvel dos Estados e Municípios e do Distrito Federal, constitui-se em Estado Democrático de Direito e tem como fundamentos:I - a soberania;II - a cidadania; III - a dignidade da pessoa humana;

${ }^{405}$ SARMENTO, Daniel; SOUZA, Neto. A Constitucionalização do direito. Ed. Lumens Juris, 2011. p 167.
} 
eles destacamos a lei 8.080, de 19 de setembro de 1990, que estabelece em seu artigo $2^{\text {o. }}$ :

\begin{abstract}
A saúde é um direito fundamental do ser humano, devendo o Estado prover as condições indispensáveis ao seu pleno exercício.

$\S 1^{\circ} \mathrm{O}$ dever do Estado de garantir a saúde consiste na formulação e execução de políticas econômicas e sociais que visem à redução de riscos de doenças e de outros agravos e no estabelecimento de condições que assegurem acesso universal e igualitário às ações e aos serviços para a sua promoção, proteção e recuperação.
\end{abstract}

Corroborando com o exposto, o art. 196 da carta magna também estabelece como dever do Estado a prestação de assistência à Saúde e garante o acesso universal e igualitário ao cidadão aos serviços e ações para sua promoção, proteção, recuperação, não devendo este direito fundamental sofrer embaraços impostos por autoridades administrativas, seja reduzindo ou dificultando o acesso.

Diante disso, não há dúvidas quanto ao dever do Estado do Rio Grande do Norte de fornecer acesso regular às unidades de tratamento intensivo aos pacientes que dele necessitam, visando às suas integridades físicas e psíquicas.

Por conseguinte, ante a omissão do poder público, seria conveniente uma postura mais severa do judiciário na implementação de políticas públicas para tentar reverter o problema, já que a alegação da ausência de recursos não merece prosperar. Nesse caso, tendo em vista que a saúde está intimamente ligada à dignidade da pessoa humana, não pode ser limitado em razão da escassez quando esta é fruto de escolha do administrador.

Logo, não pode a reserva do possível ser oponível a realização do mínimo existencial, pois entre os direitos considerados prioritários está a saúde. Nesta perspectiva, a insuficiência de recursos tem que ser demonstrada pelo poder público, não sendo admitido que a tese seja utilizada como uma desculpa genérica para a omissão estatal no campo da efetivação dos direitos fundamentais.

\title{
5 O PAPEL DA TRIBUTAÇÃO COMO INSTRUMENTO DE INCLUSÃO SOCIAL
}

A inclusão social representa um mecanismo que objetiva a alteração do meio ambiente social, no intuito de proporcionar a participação de todas as pessoas. Dessa forma, o objetivo da inclusão social não se limita apenas a evitar a discriminação e as desigualdades, mas também a promoção de políticas que proporcionem aos indivíduos pertencentes a grupos mais desfavorecidos uma participação ativa na sociedade, o que é condizente com as políticas de ação afirmativa que buscam uma inclusão social de todos por intermédio de uma postura ativa 
por parte do Estado.

Assim sendo, na promoção da inclusão social, é necessário analisar a tributação como mecanismos de mudanças sociais. Essa preocupação existe em decorrência do fato de que a implementação dos direitos sociais está intimamente ligada às questões orçamentárias e fiscais haja vista que todos os direitos são positivos, no sentido que demandam gastos públicos para a proteção.

Ocorre que tributação não exerce unicamente a função de prover o Estado dos recursos necessários para a manutenção de suas atividades, função esta classificada como fiscal dos tributos. Outrossim, o tributo deve ser utilizado numa perspectiva extrafiscal, que decorre do intervencionismo estatal, representando a ação estatal sobre a sociedade, o mercado e a livre iniciativa.

Neste diapasão, através da política extrafiscal o Estado pode estimular ou desestimular comportamentos de acordo com os interesses da sociedade, tais como a concessão de incentivos fiscais, utilização de tributação regressiva ou progressiva. Dessa forma, essas normas indutoras ao incentivarem certos comportamentos desejáveis promovem uma alteração no desenvolvimento econômico- social.

Sendo assim, é sob esta feição extrafiscal do tributo que se originam as técnicas de implementação de ações afirmativas, destacando-se: o emprego de incentivos e subsídios para as empresas empregarem portadores de deficiência, tais como redução das contribuições previdenciárias e deduções tributárias. Ademais, temos os casos se isenções de impostos sobre operações financeiras nas operações de financiamento para a aquisição de veículos por pessoas portadoras de deficiência. Vale destacar também o programa de ação afirmativa, embasado em benefícios fiscais, na área da educação: o PROUNI institucionalizado pela lei no 11.096 de 13 de janeiro de 2005 que é direcionada a programa de bolsa de estudos em instituições de ensino superior privadas.

Por estes motivos, percebe-se que a extrafiscalidade da tributação tem interferido de forma positiva na concretização das políticas públicas, já que a mesma induz os comportamentos dos particulares com vistas à concretização dos direitos fundamentais. Além disso, a própria CFRB possui preocupação com o ideal de justiça social, abarcando as medidas de ação afirmativa. Com efeito, através da concessão de benefícios físcais tem sido possível proporcionar uma maior inclusão social.

\section{CONSIDERAÇÕES FINAIS}


Os direitos sociais são os direitos humanos também chamados de direitos da segunda geração, que tentam garantir o mínimo de dignidade e igualdade aos seres humanos e suprimir as desigualdades sociais, fazendo-se necessário que sua efetivação seja matéria de consciência social do sistema jurídico.

Notou-se que o Welfare State foi o precursor dos ideais de que o Estado é o agente responsável pela democracia social, visto que é através do poder governamental que resultam todos os outros processos reguladores da sociedade, que proporcionam a efetivação dos direitos sociais conferidos na Constituição Federativa da República Brasileira de 1988. Tal visão será abordada com maior precisão no próximo tópico, que conceitua e explana as políticas públicas.

Inferiu-se que Políticas Públicas consistem em instrumentos legítimos de efetivação de direitos fundamentais resultantes do estudo de um conjunto de processos interligados para realizarem projetos úteis e necessários à sociedade, formulados de acordo com os recursos estatais disponíveis, pondo em prática, dessa forma, os programas de ação governamental.

Percebeu-se que a cidadania é um tema de grande monta, garantido legalmente no art. $1^{\mathrm{o}}$ da CRFB/88. Possui acepção ampla e histórica iniciada pelo sociólogo T.H. Marshall, que ficou conhecido pelos ideais de extensão dos direitos civis, políticos e sociais para toda a população. Além de tudo, a cidadania almeja equilibrar as condições de inclusão dos cidadãos, proporcionando direitos, deveres e garantindo direitos fundamentais, tais como a igualdade e a solidariedade.

Ademais, restou demonstrado que o ativismo judicial tem relação direta com as políticas públicas, uma vez que o Judiciário é o guardião da Constituição e deve fazê-la valer, em nome dos direitos fundamentais e dos valores e procedimentos democráticos, inclusive em face dos outros Poderes. Essa atuação deve se ater principalmente na implementação de medidas que assegurem a garantia do direito social à saúde no caso do Estado Rio grande do Norte.

E por último, pretendeu-se analisar a forma como a tributação tem influenciado positivamente na implementação das políticas de inclusão social, em especial as ações afirmativas, que buscam a inclusão social de grupos desfavorecidos ao longo da evolução da sociedade.

\section{REFERÊNCIAS}

BARROS, Marco Aurélio de Freitas. O ministério público social e o controle de políticas públicas no Brasil. Revista Pesquisas Jurídicas. Vol.01, n.1. jul-dez. 2012. 
BARROSO, Luíz Roberto. Judicialização, ativismo judicial e legitimidade democrática. Disponível em:

$<$ http://www.oab.org.br/editora/revista/users/revista/1235066670174218181901.pdf $>$. Acesso em: 26 abr. 2016.

BERTRAMELLO, Rafael. Os direitos socais: conceito, finalidade e teorias. Atualidades do Direito. Disponível em: < http://atualidadesdodireito.com.br/rafaelbertramello/2013/06/29/osdireitos-sociais-conceito-finalidade-e-teorias/>. Acesso em: 26 abr. 2016.

BRASIL. Constituição. Constituição Federativa do Brasil. Brasília: Senado Federal, 1988.

BITTAR, Eduardo C.B. Ética, educação, cidadania e direitos humanos: Estudos filosóficos entre cosmopolitismo e responsabilidade social. São Paulo. Manole, 2004. BUCCI, Maria Paula Dallari. Direito Administrativo e Políticas Públicas. São Paulo: Saraiva, 2012.

CAMARGO, Orson. O que é cidadania? Brasil escola. Disponível em: < http://www.brasilescola.com/sociologia/cidadania-ou-estadania.htm>. Acesso em: 20 mar. 2016.

CAMPELLO, Roberto. Quase 30 pacientes aguardam por leito de UTI no Hospital Walfredo Gurgel. Disponível em: $<$ http://jornaldehoje.com.br/quase-30-pacientes-aguardam-por-leitode-uti-no-hospital-walfredo-gurgel/ >.Acesso em: 26 abr. de 2016.

CARVALHO, José Murilo. Cidadania no Brasil: o longo caminho. Rio de Janeiro: Civilização Brasileira, 2001. p. 219-29.

CARVALHO, Paulo de Barros. Curso de Direito Tributário. 23 ed. São Paulo: Saraiva, 2011.

CAVALCANTE, Tatiana Maria Náufel. Cidadania e Acesso à justiça. Disponível em: < http://www.egov.ufsc.br/portal/sites/default/files/anexos/32195-38277-1-PB.pdf $>$. Acesso em: 20 jan. 2016.

DINIZ, Maria Helena. Dicionário Jurídico. Vol. 1. 2ª ed. São Paulo : Saraiva, 2005, p. 692.

FERNANDÉZ, Antoni. Las políticas públicas. In: BADIA, Miquel Caminal (Editor). Manual de Ciencia Política. 3 ed. Madrid: Tecnos, 2010. 
GOMES, Fábio Guedes. Conflito social e Welfare State: Estado e desenvolvimento social no Brasil. Disponível em: < http://www.scielo.br/pdf/rap/v40n2/v40n2a03.pdf>. Acesso em: 26 abr. 2016.

GONÇALVES, Alcindo. Políticas públicas e a ciência política. In: BUCCI, Maria Paula Dallari (org.). Políticas públicas: reflexões sobre o conceito jurídico. São Paulo: Saraiva, 2006, p. 75-96.

KRELL, Andréas J. Direitos sociais e controle judicial no Brasil e na Alemanha, cit., p. 51.

MARSHALL, T. H. Cidadania, classe social e status. Rio de Janeiro: Zahar, 1967.

MENDES, G; COELHO, I; BRANCO, P. Curso de Direito Constitucional. 2 ed. São Paulo: Saraiva, 2008.

RABELO, Luiz Otávio. Direito tributário como instrumento de inclusão social. Disponível em: <http://www.pgfn.fazenda.gov.br/revista-pgfn/ano-i-numero-i/luiz.pdf > . Acesso em:20 abr. de 2016.

SABBAG, Eduardo. Manual de Direito Tributário. 4 ed. São Paulo: Saraiva, 2012.

SARMENTO, Daniel; SOUZA, Neto. A Constitucionalização do direito. Ed. Lumens Juris, 2011.

SILVA, José Afonso da. Curso de Direito Constitucional Positivo. $32^{\mathrm{a}}$ ed. rev. e atual. - São Paulo: Malheiros Editores, 2009, p. 285.

SUPERIOR TRIBUNAL FEDERAL. Jurisprudências. Disponível em: < http://stf.jusbrasil.com.br/jurisprudencia/20627236/acao-direta-de-inconstitucionalidade-adi4277-df-stf >. Acesso em: 25 abr. 2016.

\section{PUBLIC POLICY ANALYSIS OF THE CONDITIONS OF STATE HOSPITAL MONSENHOR Walfredo GURGEL}


It examines public policies in Brazil, dialectically, through a historical analysis, with doctrinal basis of the study of social rights, citizenship and classical vision of the welfare state. It studies the judicial activism, which has its reputed use as institutionally relevant and appropriate to the implementation of public policies, since before the inertia of some institutions, passes the judiciary to play positions to fill this omission, so that the fundamental rights they can be realized. The search still evidence the theory developed in a particular case, from a topic problematic, it analysis in order to demonstrate the chaotic situation of health in the state of Rio Grande do Norte, emphasizing the problem of ICU beds in Walfredo Gurgel Hospital and seeking a practical solution to solve this problem, based on the constitutional right to health and human dignity. It studies to taxation as a mechanism for social change, since the tax is use in an extrafiscal perspective, due to the state interventionism, representing the state action on society, the market and free enterprise. Finally, it seeks to demonstrate how the tax has positively influenced the implementation of social inclusion policies, especially affirmative action aimed at social inclusion of disadvantaged groups throughout the evolution of society.

Keywords: Public Policies. Taxation. Tax Law. 